\title{
Relationship between household wealth and childhood immunization in core-North Nigeria
}

\author{
Ayo Adebowale ${ }^{1,2}$, Taiwo Obembe ${ }^{3}$ Eniola Bamgboye ${ }^{2}$
}

1. University of Cape Town, Centre for Actuarial research.

2. University of Ibadan, Epidemiology and Medical statistics.

3. University of Ibadan, Health Policy and Management.

\begin{abstract}
Background: Childhood immunization rate is lowest in the core-North Nigeria. We examined the relationship between inequality in household wealth and complete childhood immunization in that part of the country.

Methods: A cross-sectional survey was conducted among 4079 mothers with children 12-23 months of age. Children were considered 'fully-immunized' if they received all the vaccines included in the immunization schedule. Data were analyzed using descriptive statistics and logistic regression models $(\alpha=5.0 \%)$.

Results: About 39\% and 5.0\% children of the rich and poor received complete immunization respectively. Also, $64.2 \%$ and 49.6\% children of the rich women received BCG and DPT 3 compared to $15.9 \%$ and $8.7 \%$ observed among the children of the poor. Higher proportion of children from poor households (40.6\%) received no immunization than $20.8 \%$ found from the rich households. The likelihood of receiving complete immunization was 1.95(C.I=1.35-2.80, $\mathrm{p}<0.001)$ times higher among the children of the rich than the poor. Other important predictors of childhood immunization were age, religion, media access, working status, husband's education, prenatal attendants and delivery place.

Conclusion: Disparities existed in childhood immunization between the poor and rich in the core-North part of Nigeria. Policy makers should institute effective interventions that will assist children from poor households to improve their immunization access.
\end{abstract}

Keywords: Household wealth, immunization, child health, Nigeria.

DOI: https://dx.doi.org/10.4314/ahs.v19i1.33

Cite as: Adebowale A, Obembe T, E B. Relationship between household wealth and childhood immunization in core-North Nigeria. Afri Health Sci. 2019;19(1). 1582-1593. bttps://dx.doi.org/10.4314/abs.v19i1.33

\section{Introduction}

Immunization averts an estimated 2 to 3 million deaths yearly from diphtheria, tetanus, pertussis and measles. However, global coverage remains below the WHO recommended rates. ${ }^{1}$ In addition, immunization is a known strategy for preventing childhoodmortality not only by combating childhood killer diseases but also by providing a platform for assess to broader health care services. ${ }^{2}$

\section{Corresponding author:}

Ayo Adebowale,

University of Cape Town,

Centre for Actuarial Research,

University of Ibadan,

Email: Adehamilt2008@yahoo.com
Nevertheless, there is a great variation in the immunization coverage rates globally with sub-Saharan Africa having the worst indices. ${ }^{3-6}$ Nigeria, the most populous African Nation is among countries with low rates of immunization coverage in sub-Saharan Africa. ${ }^{3,7}$

In cognizance of the persistently low immunization uptake, the Nigerian Government introduced several child survival strategies and the existing ones were expanded to strengthening routine immunization system. ${ }^{8}$ For its implementation, several supplemental immunization campaigns were steered to ensure rapid improvement in the immunization coverage among children and to forestall or respond to disease outbreaks. ${ }^{8-9}$ Despite government efforts, the level of immunization coverage in many parts of Nigeria is far from optimal and equitable with CoreNorth Nigeria consistently recording the least coverage

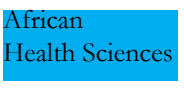

(C) 2019 Adebowale et al. Licensee African Health Sciences. This is an Open Access article distributed under the terms of the Creative commons Attribution License (https://creativecommons.org/licenses/BY/4.0), which permits unrestricted use, distribution, and reproduction in any medium, provided the original work is properly cited. 
level. ${ }^{10,11}$ According to Sustainable Development Goals (SDGs), there is a mandate for government to ensure healthy lives and promote wellbeing for all and reduce inequality within and among countries by 2030 .

In spite of Nigeria Government's determination to uphold the tenets of the SDGs, huge challenges still remain in the country with respect to child survival. The infant and under-five mortality rates are still high at 69 and 128 per 1,000 livebirths respectively. ${ }^{12}$ It is worrisome that these indices are remarkably higher in the core-North which comprises of North-East and North-West part of Nigeria than these national estimates ${ }^{12}$ It is indispensable to note that any efforts gearing towards fertility and childhood mortality reduction will be unrealizable, if the level of childhood immunization coverage remains low in Nigeria. The core-North in particular is faced with the challenge of preventable diseases peculiar to tropical environment such as: measles, tetanus, whooping cough and polio. ${ }^{12}$ Researchers have shown that childhood morbidity and mortality are preventable by setting up a health system that can deliver vaccines to all children during the first year of life and complete immunization before 23 months of age., 213,14

There is an increasing body of literature divulging various sociodemographic factors as predictors of immunization coverage rates among children aged 12-23 months in different population groups. ${ }^{6,15-17}$ among which household wealth is often cited. ${ }^{10,18-20}$ In a study conducted in $45 \mathrm{Ga}$ vi-supported countries, where inequalities in vaccination coverage was examined, level of wealth index poverty was one of the dimensions found to be associated with the largest inequalities in childhood immunization coverage. ${ }^{21}$ It has also been proved that complete vaccination probability was higher among children from highest wealth quintile households compared with the poorest. ${ }^{16}$

Generally, there is inequality in wealth distribution and a wide gap exists between the rich and the poor in terms of accessing health care even at public health facilities in Nigeria where majority of its population earn less than two dollars a day. ${ }^{12}$ The gap becomes wider if the poor's place of residence is far from the health facility which is the peculiar situation in the core-North Nigeria. ${ }^{12,19}$ Unfortunately, not all health facilities can admin- ister childhood immunization vaccines in Nigeria, they are only available at designated facilities. In an instance where the location of such facility is far from home of an impoverished mother, lack of transportation fare can deprive the woman from immunizing her child. Likewise, repeated failed attempts as a result of vaccine and equipment shortage can be equally discouraging for a mother striving to immunize her child in a facility.These circumstances all have dire implications on completeness of immunization of the child. In the core-North Nigeria, there is a large disparity in wealth distribution between the rich and the poor, therefore, this is likely to cause variation in health care access between them. The inequality in household wealth has been identified to be responsible for the low immunization coverage rates in areas characterized by core-north situation ${ }^{10,19}$, however this is yet to be fully documented in Northern Nigeria.

Examining the difference in full immunization coverage between the rich and the poor will assist immunization programme managers in their quest for improvement in immunization coverage in the core-North part of Nigeria. Reduction in childhood mortality level in core-North is likely to be achieved if childhood immunization is fully accessed in the region.

\section{Methods}

\section{Study area}

This study was conducted in the North East (NE) and North West (NW) regions in Nigeria. The two regions have similar socio-demographic characteristics to an extent. They are predominantly Muslims and theliteracy level is lowest among the people living in the region compared to other regions in Nigeria. ${ }^{22}$ The total fertility rate is highest in the country $(\mathrm{TFR}=6.3$ (N.E) and TFR=6.7(N.W)).12 The under-five mortality rate in NE and NW are 160 and 185 per 1000 live birth respectively while the infant mortality rate was $77 / 1,000$ live birth in the N.E, it was $89 / 1000$ live birth in the N.W. ${ }^{12}$ It is important to note that public health facilities in Nigeria are underserved but there are variations between and within regions in Nigeria. The pattern of accessing health care including post-natal care is similar in the NE and NW.12 Men still play a domineering role on the decision of women to access health care for themselves and their children in the region. ${ }^{12}$ Although, this is a common practice among Nigeria families, but the behavior is more 
prevalent among the families in core-North part of the country.

\section{Study design and sample selection}

The study utilised a secondary data analysis of 2013 Nigeria Demographic and Health Survey and the analysis focused on sample of women currently having children aged 12-23 months in the NE and NW. The survey data was large and nationally representative. It also allows sub-regional analysis of the data across all spectrum of health and demographic research. Cluster design sampling technique was used for data collection. This involved the use of complete list of enumeration areas (EAs) that were prepared for the last population census exercise in Nigeria which was conducted in 2006. The primary sampling unit was defined on the basis of EAs with each EA constituting a cluster where a fixed sample of 45 households were selected per cluster. Samples were selected using a stratified three-stage cluster design taking into consideration of rural-urban dichotomy of Nigeria. Specifically, a sample of 4079 was used which consisted of 3349 and 730 women from poor and rich households respectively.

\section{Outcome variable}

The outcome variable was complete immunization status. Vaccination coverage information focused on children 12-23 months of age. According to vaccination schedule in Nigeria, a child is considered fully immunized if he or she has received Bacille Calmette-Guerin (BCG) vaccination against tuberculosis which is given at birth; three doses of DPT vaccine to prevent diphtheria, pertussis, and tetanus; at least three doses of oral polio vaccine (OPV); and one dose of measles vaccine. These vaccines should be received during the first year of life. ${ }^{23}$ Although, it is expected that within the first 12-23 months of life, all basic vaccinations should have been received by the children. Thus, a child is said to be fully immunized if he had received all of the immunizations recommended in the official immunization schedule while, a partially immu- nized child has not received all of the immunizations, but he or she has received at least one of the vaccines.Lastly, an unvaccinated child is the one who has not received any of the stipulated vaccines in the schedule.

Information on immunization coverage was collected during the survey in two ways-visual verification of vaccination cards or by verbal reporting.. For those who could provide their cards, the research assistants entered the vaccination dates into the questionnaires. However, in situations where no vaccination card was presented or in cases where a vaccine had not been recorded on the card, the respondent was asked to recount the vaccines that had been administered to her child. ${ }^{12}$

\section{Data analyses}

Data were weighted by creating avariable using the sampling weight. This is necessary because cluster design approach was used for data collection and there would be a need to stretch the data to increase coverage. Frequency distribution, Chi-square and logistic regression were used for data analyses. The Chi-square was used to examine factors that are associated with immunization among children. In this context, both child and maternal characteristics were investigated. At the level of multivariate analysis, binary logistic regression was used to identify factors influencing completeness of immunization among children age 12-23 months. Here, the categories was dichotomized as 1 (if the child had completed the needed immunization) and 0 (if otherwise). Using this statistical tool, four regression models were generated. In the first model, wealth index and health related factors were introduced into the equation to ascertain the influence of these factors on the relationship between wealth and immunization. The second and third models were generated to identify predictors of complete immunization among the rich and the poor respectively. The last model is the full model obtained by pooling all the data for both rich and poor together to see if household wealth will retain its strength with respect to its relationship with the outcome variable in the midst of other factors. The models are illustrated in equations (1)-(4).

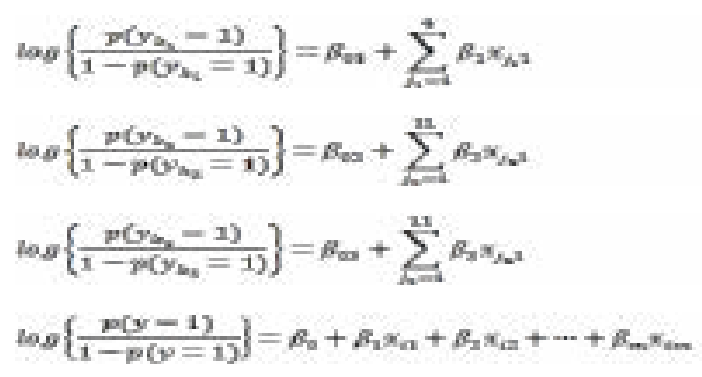




\section{Results}

The data show that across all the immunization vaccines received by the children, the prevalence was consistently higher among the rich women than the poor. While $38.6 \%$ of the children of the rich received complete immunization, only $5.0 \%$ of the poor did. About $64.2 \%$ and $49.6 \%$ children of the rich women received BCG and DPT 3 compared with $15.9 \%$ and $8.7 \%$ observed among the children of the poor respectively. Also, $57.9 \%$ vs $17.8 \%$ and $61.2 \%$ vs $52.1 \%$ of the children of mothers who belong to rich and poor wealth category received oral polio and polio 3 respectively. Approximately, 56\% of the children of the rich women had been immunized against measles whereas only $17.1 \%$ of the poor women received the vaccine. Complete DPT was least taken by the children across the two wealth categories, while oral polio $(17.8 \%$ ) was mostly taken by the children of the poor, BCG $(64.2 \%)$ was mostly received by the children of the rich.

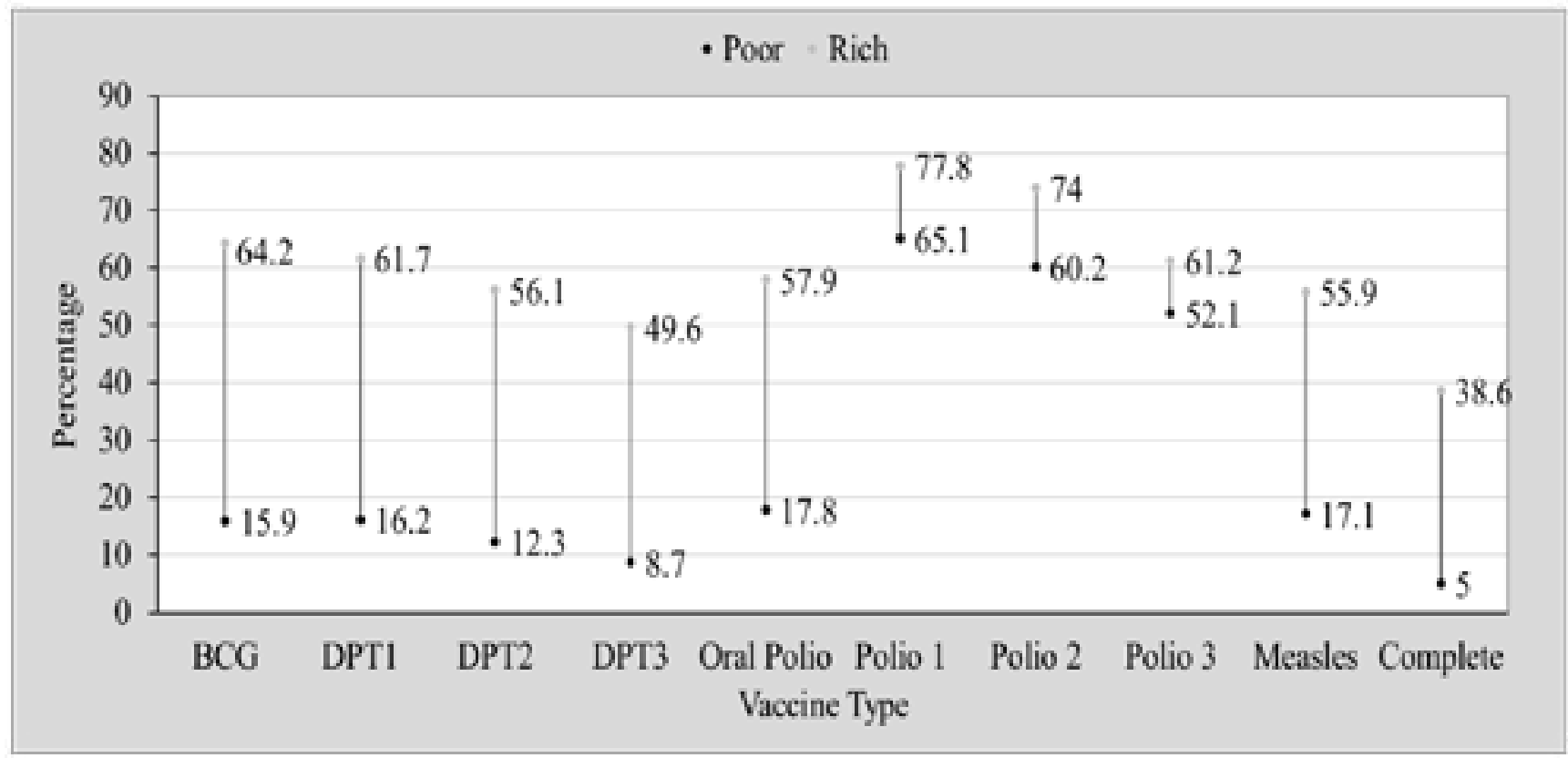

Figure 1: Prevalence of immunization by household wealth among children aged 12-23 months in Nigeria (NDHS, 2013)

\section{NDHS: Nigeria Demographic Health and Survey}

The distribution of the women by household wealth status who provided information on the immunization status of their children aged 12-23 months are as shown in Table 1 below. The age distribution shows that women in age group 15-24 years constituted the highest proportion of women from households with poor wealth (31.5\%). Although, in the two wealth categories, there was an equitable distribution of women in different age groups. It is striking that $87.7 \%$ of women in poor wealth category do not have any formal education compared with $30.8 \%$ of those in rich wealth class. While $51.8 \%$ of rich class women had at least secondary education, only $3.1 \%$ was observed among women in poor wealth class. Eighty four percent and $73.3 \%$ of the women in poor and rich wealth class respectively, reported that their husband/partner alone has a final decision on their health care. In terms of the pre-natal attendance of the women during the pregnancy of the investigated children, $64.2 \%$ and $9.6 \%$ of the poor and rich respectively did not seek any ante-natal care. 
Table 1: Percentage distribution of the respondents by background characteristics (NDHS, 2013)

\begin{tabular}{|c|c|c|c|c|}
\hline \multirow[t]{2}{*}{ Background characteristics } & \multicolumn{2}{|l|}{ Poor } & \multicolumn{2}{|l|}{ Rich } \\
\hline & Frequency & $\%$ & Frequency & $\%$ \\
\hline Total & 3349 & 100.0 & 730 & 100.0 \\
\hline \multicolumn{5}{|l|}{ Age } \\
\hline $15-24$ & 1054 & 31.5 & 173 & 23.7 \\
\hline $25-29$ & 866 & 25.9 & 189 & 25.9 \\
\hline $30-34$ & 588 & 17.6 & 174 & 23.8 \\
\hline $35-49$ & 840 & 25.1 & 194 & 26.5 \\
\hline \multicolumn{5}{|l|}{ Child's birth order } \\
\hline 1st Birth & 489 & 14.6 & 113 & 15.4 \\
\hline $2-3$ & 931 & 27.8 & 216 & 29.6 \\
\hline $4-5$ & 802 & 24.0 & 199 & 27.2 \\
\hline $6+$ & 1126 & 33.6 & 202 & 27.7 \\
\hline \multicolumn{5}{|l|}{ Religion } \\
\hline Christianity & 172 & 5.1 & 153 & 20.9 \\
\hline Islam & 3147 & 94.0 & 575 & 78.8 \\
\hline Others & 30 & 0.9 & 2 & 0.3 \\
\hline \multicolumn{5}{|l|}{ Media Access } \\
\hline None & 1926 & 57.5 & 60 & 8.2 \\
\hline Low & 1266 & 37.8 & 223 & 30.5 \\
\hline Medium & 153 & 4.6 & 331 & 45.3 \\
\hline High & 4 & 0.1 & 117 & 16.0 \\
\hline \multicolumn{5}{|l|}{ Level of Education } \\
\hline No education & 2938 & 87.7 & 225 & 30.8 \\
\hline Primary & 309 & 9.2 & 127 & 17.4 \\
\hline Secondary & 99 & 3.0 & 287 & 39.4 \\
\hline Higher & 2 & 0.1 & 91 & 12.4 \\
\hline \multicolumn{5}{|l|}{ Working status } \\
\hline No & 1403 & 41.9 & 258 & 35.4 \\
\hline Yes & 1945 & 58.1 & 472 & 64.6 \\
\hline \multicolumn{5}{|l|}{ Husband/Partner's level of education } \\
\hline No education & 2515 & 75.1 & 145 & 19.9 \\
\hline Primary & 505 & 15.1 & 71 & 9.8 \\
\hline Secondary & 277 & 8.3 & 260 & 35.6 \\
\hline Higher & 51 & 1.5 & 254 & 34.8 \\
\hline \multicolumn{5}{|l|}{ Decision on health care } \\
\hline Respondent alone & 33 & 1.0 & 39 & 5.4 \\
\hline Respondent and husband/partner & 494 & 14.7 & 156 & 21.3 \\
\hline Husband/partner alone & 2822 & 84.3 & 535 & 73.3 \\
\hline \multicolumn{5}{|l|}{ Ethnicity } \\
\hline Hausa/Fulani & 2628 & 78.5 & 465 & 63.6 \\
\hline Other tribes & 721 & 21.5 & 265 & 36.4 \\
\hline \multicolumn{5}{|l|}{ Pre-natal Attendant } \\
\hline None & 2148 & 64.2 & 70 & 9.6 \\
\hline Semi-skilled & 284 & 8.5 & 34 & 4.6 \\
\hline Skilled & 916 & 27.4 & 626 & 85.8 \\
\hline \multicolumn{5}{|l|}{ Place of Delivery } \\
\hline Home & 3120 & 93.2 & 392 & 53.7 \\
\hline Health Facility & 229 & 6.8 & 338 & 46.3 \\
\hline
\end{tabular}


In Figure 2, the data shows that $20.8 \%$ of children from rich households did not receive any immunization as against $40.6 \%$ of children of women from poor households. Higher proportion of children of poor women
(54.4\%) had incomplete immunization compared with $40.6 \%$ of women who belong to rich households. The gap between the children of women who received complete immunization and that of the poor was $33.6 \%$ $(38.6 \%$ vs 5.0$)$.

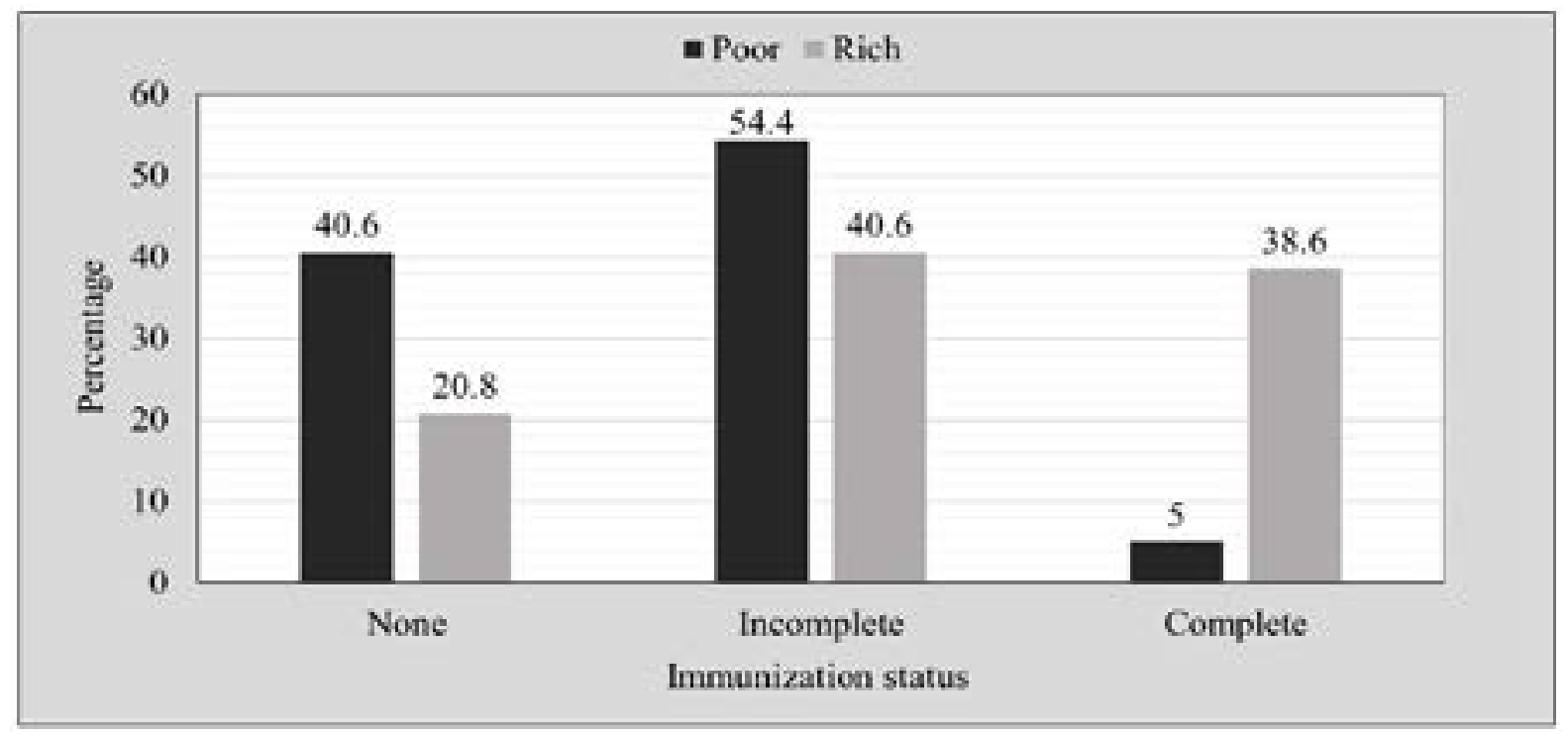

Figure 2: Percentage distribution of children aged 12-23 months by immunization status according to household wealth (NDHS, 2013)

\section{NDHS: Nigeria Demographic Health and Survey}

The data depicts that mothers in the youngest age group reported least coverage of childhood immunization in the two wealth classes and the coverage was more pronounced among the children of Christian mothers than their Muslim counterparts. About 25.6\% of Christians in the poor wealth class had fully immunized their children compared with only 3.8\% among the Muslims. Similar pattern was observed for the rich class but with much higher prevalence $(78.0 \%$ and $28.2 \%$ among the children of Christians and Muslim respectively). While only 3.6\% of children of women with no formal education among the poor class had received complete immunization, $18.5 \%$ was reported among the rich class. Among mothers with at least secondary education, $20.8 \%$ of the children of the poor and $51.2 \%$ of the rich had complete immunization. However, in the two classes, the data showed that an increase in level of education was associated with increasing childhood immunization level. The percentage of childhood immunization was higher among the working class women than those who are not working for the two wealth groups. 
Table 2: Percentage distribution of children aged 12-23 months by immunization status according to background characteristics (NDHS, 2013)

\begin{tabular}{|c|c|c|c|c|c|c|}
\hline \multirow{2}{*}{$\begin{array}{l}\text { Background } \\
\text { characteristics }\end{array}$} & \multicolumn{3}{|l|}{ Poor } & \multicolumn{3}{|l|}{ Rich } \\
\hline & $\begin{array}{l}\text { Complete } \\
\text { immunizn }\end{array}$ & Total women & $\begin{array}{l}\chi^{2} \text {-value } \\
\text { (p-value) }\end{array}$ & $\begin{array}{l}\text { Complete } \\
\text { immunizn }\end{array}$ & Total women & $\begin{array}{l}\chi^{2} \text {-value } \\
\text { (p-value) }\end{array}$ \\
\hline Total & $5.0(162)$ & 3255 & & $38.6(274)$ & 710 & \\
\hline \multicolumn{2}{|l|}{ Mother's age } & & \multicolumn{2}{|l|}{$22.0^{* *}$} & & \multirow{5}{*}{$\begin{array}{l}13.8^{*} \\
(0.031)\end{array}$} \\
\hline $15-24$ & $3.7(38)$ & 1023 & \multirow[t]{4}{*}{$(0.001)$} & $27.7(46)$ & 166 & \\
\hline $25-29$ & $5.8(49)$ & 843 & & $44.4(83)$ & 187 & \\
\hline $30-34$ & $4.4(25)$ & 574 & & $42.3(71)$ & 168 & \\
\hline $35-49$ & $6.0(49)$ & 815 & & $39.2(74)$ & 189 & \\
\hline \multicolumn{2}{|l|}{ Child's birth order } & & \multicolumn{2}{|l|}{$19.7^{* *}$} & & \multirow{5}{*}{$\begin{array}{l}17.3^{* *} \\
(0.008)\end{array}$} \\
\hline 1st Birth & $3.4(16)$ & 473 & \multirow[t]{4}{*}{$(0.003)$} & $44.4(48)$ & 108 & \\
\hline $2-3$ & $5.4(49)$ & 912 & & $38.4(81)$ & 211 & \\
\hline $4-5$ & $4.9(38)$ & 783 & & $46.4(90)$ & 194 & \\
\hline $6+$ & $5.4(59)$ & 1088 & & $27.9(55)$ & 197 & \\
\hline \multicolumn{3}{|l|}{ Religion } & \multicolumn{2}{|l|}{$167.7 * * *$} & & \multirow{4}{*}{$\begin{array}{l}125.6^{* * *} \\
(<0.001)\end{array}$} \\
\hline Christianity & $25.6(43)$ & 168 & \multirow[t]{3}{*}{$(<0.001)$} & $78.0(117)$ & 150 & \\
\hline Islam & $3.8(117)$ & 3056 & & $28.2(157)$ & 557 & \\
\hline Others & $6.9(2)$ & 29 & & $0.0(0)$ & 2 & \\
\hline \multicolumn{3}{|l|}{ Media Access } & \multicolumn{2}{|l|}{$91.5 * * *$} & & \multirow{5}{*}{$\begin{array}{l}88.6^{* * *} \\
(<0.001)\end{array}$} \\
\hline None & $3.5(65)$ & 1883 & \multirow[t]{4}{*}{$(<0.001)$} & $10.2(6)$ & 59 & \\
\hline Low & $6.1(74)$ & 1218 & & $29.4(63)$ & 214 & \\
\hline Medium & $14.7(22)$ & 150 & & $43.0(139)$ & 323 & \\
\hline High & $25.0(1)$ & 4 & & $57.5(65)$ & 113 & \\
\hline \multicolumn{3}{|l|}{ Level of Education } & \multicolumn{2}{|l|}{$128.3 * * *$} & & \multirow{4}{*}{$\begin{array}{l}79.1 * * * \\
(<0.001)\end{array}$} \\
\hline No education & $3.6(102)$ & 2850 & $(<0.001)$ & $18.5(40)$ & 216 & \\
\hline Primary & $12.9(39)$ & 303 & & $36.3(45)$ & 124 & \\
\hline Secondary + & $20.8(21)$ & 101 & & $51.2(189)$ & 369 & \\
\hline Working status & & & $78.3 * * *$ & & & $38.6^{* * *}$ \\
\hline No & $2.8(38)$ & 1371 & $(<0.001)$ & $26.5(67)$ & 253 & $(<0.001)$ \\
\hline Yes & $6.5(123)$ & 1883 & & $45.3(207)$ & 457 & \\
\hline Husband/Partner's 1 & of education & & $169.8^{* * *}$ & & & $35.6 * * *$ \\
\hline No education & $2.9(71)$ & 2446 & $(<0.001)$ & $19.7(28)$ & 142 & $(<0.001)$ \\
\hline Primary & $7.4(36)$ & 487 & & $39.4(28)$ & 71 & \\
\hline Secondary+ & $17.1(55)$ & 321 & & $44.1(219)$ & 497 & \\
\hline Decision on health & & & $41.9^{* * *}$ & & & $56.4 * * *$ \\
\hline Respondent alone & $6.2(2)$ & 32 & $(<0.001)$ & $80.0(32)$ & 40 & $(<0.001)$ \\
\hline Respt.\&partner & $10.0(48)$ & 481 & & $53.0(79)$ & 149 & \\
\hline Partner alone & $4.0(111)$ & 2741 & & $31.3(163)$ & 520 & \\
\hline Ethnicity & & & $144.0 * * *$ & & & $50.2 * * *$ \\
\hline Hausa/Fulani & $3.4(87)$ & 2546 & $(<0.001)$ & $28.8(129)$ & 448 & $(<0.001)$ \\
\hline Other tribes & $10.6(75)$ & 709 & & $55.6(145)$ & 261 & \\
\hline Pre-natal Attendant & & & $204.8 * * *$ & & & $104.6 * * *$ \\
\hline None & $1.3(28)$ & 2094 & $(<0.001)$ & $4.6(3)$ & 65 & $(<0.001)$ \\
\hline Semi-skilled & $11.3(31)$ & 274 & & $28.1(9)$ & 32 & \\
\hline Skilled & $11.5(102)$ & 886 & & $42.8(262)$ & 612 & \\
\hline Place of Delivery & & & $76.8^{* * *}$ & & & $90.4 * * *$ \\
\hline Home & $4.1(125)$ & 3031 & $(<0.001)$ & $23.0(87)$ & 379 & $(<0.001)$ \\
\hline Health Facility & $16.5(37)$ & 224 & & $56.5(187)$ & 331 & \\
\hline
\end{tabular}

The unadjusted model showed that the likelihood of complete childhood immunization receipt was 12.0 (C.I $=9.66$ $-14.97, \mathrm{p}<0.001)$ times higher among the children of the rich than the poor. The analysis result as shown in Table 3 consists of 4 models. In the first model, the likelihood of receiving complete immunization was 3.8 (C.I $=2.94$
- 4.95, $\mathrm{p}<0.001)$ times higher among children of mothers from rich homes than those from poor homes. The model 2 was constructed based on information from the poor households. In this model, variables like religion, media access, work status, husband's education, ethnicity, prenatal attendants and delivery place were identified 
as the predictors of complete childhood immunization. Similar to model 2, the third model was solely based on information from the women from the rich households. Age, religion, media access, prenatal attendants and delivery place were found as the predictors of complete childhood immunization among the children of women from the rich class.

The last model is the full model where all the variables, wealth class inclusive were introduced into the regression model to see how others variables influence the relation- ship between wealth class and complete immunization among children age 12-23 months in the study area. The data shows that wealth class was an important predictor of full immunization coverage in the study area and the chances of complete immunization was $(\mathrm{AOR}=1.95$; C.I $=1.35-2.80, \mathrm{p}<0.001)$ times higher among the children of the rich than that of the poor. The identified factors important in this differential between the childhood immunization of the rich and the poor were age, religion, media access, working status, husband's education, prenatal attendants and delivery place.

Table 3: Multiple logistic regression model of factors predictors of complete immunization among children aged 12-23 months according to background characteristics (NDHS, 2013)

\begin{tabular}{|c|c|c|c|c|}
\hline \multirow{2}{*}{$\begin{array}{l}\text { Background } \\
\text { characteristics }\end{array}$} & \multirow{2}{*}{$\begin{array}{l}\text { Model } 1 \\
\text { AOR(95\% C.I) }\end{array}$} & \multirow{2}{*}{$\begin{array}{l}\text { Model } 2 \\
\text { AOR(95\% C.I) } \\
\end{array}$} & \multirow{2}{*}{$\begin{array}{l}\text { Model } 3 \\
\text { AOR(95\% C.I) } \\
\end{array}$} & \multirow{2}{*}{$\begin{array}{l}\text { Full model } \\
\text { AOR(95\% C.I) }\end{array}$} \\
\hline & & & & \\
\hline \multicolumn{5}{|l|}{ Mother's age } \\
\hline $15-24$ & & 1 & 1 & 1 \\
\hline $25-29$ & & $1.73(0.99-3.01)$ & $2.38(1.27-4.46)^{* *}$ & $1.95(1.29-2.93)^{* *}$ \\
\hline $30-34$ & & $1.31(0.65-2.63)$ & $1.61(0.77-3.34)$ & $1.42(0.87-2.32)$ \\
\hline $35-49$ & & $1.80(0.86-3.72)$ & $2.82(1.21-6.55)^{*}$ & $2.08(1.21-3.57)^{* *}$ \\
\hline \multicolumn{5}{|l|}{ Child's birth order } \\
\hline 1st Birth & & 1 & 1 & 1 \\
\hline $2-3$ & & $1.21(0.62-2.34)$ & $0.71(0.37-1.36)$ & $0.92(0.58-1.43)$ \\
\hline $4-5$ & & $0.95(0.43-2.06)$ & $0.73(0.34-1.54)$ & $0.83(0.49-1.38)$ \\
\hline $6+$ & & $0.96(0.41-2.26)$ & $0.49(0.19-1.21$ & $0.69(0.38-1.26)$ \\
\hline \multicolumn{5}{|l|}{ Household Wealth } \\
\hline Poor & 1 & & & 1 \\
\hline Rich & $3.82(2.94-4.95) * * *$ & & & $1.95(1.35-2.80)^{* * *}$ \\
\hline \multicolumn{5}{|l|}{ Religion } \\
\hline Christianity & & 1 & 1 & 1 \\
\hline Islam & & $0.52(0.28-0.96)^{*}$ & $0.19(0.09-0.37)^{* *}$ & $0.31(0.20-0.48)^{* * *}$ \\
\hline Others & & $1.21(0.26-5.66)$ & & $0.71(0.15-3.20)$ \\
\hline \multicolumn{5}{|l|}{ Media Access } \\
\hline None & & 1 & 1 & 1 \\
\hline Low & & $1.61(1.09-2.37)^{*}$ & $1.30(0.49-3.37)$ & $1.59(1.12-2.24)^{* *}$ \\
\hline Medium & & $2.99(1.64-5.42)^{* * *}$ & $1.97(0.76-5.02)$ & $2.46(1.59-3.78)^{* * *}$ \\
\hline High & & $0.83(0.04-15.62)$ & $3.08(1.09-8.69) *$ & $3.49(1.90-6.40)^{* * *}$ \\
\hline \multicolumn{5}{|l|}{ Level of Education } \\
\hline No education & & 1 & 1 & 1 \\
\hline Primary & & $1.16(0.71-1.87)$ & $1.44(0.78-2.64)$ & $1.24(0.85-1.80)$ \\
\hline Secondary + & & $0.97(0.48-1.96)$ & $1.41(0.79-2.48)$ & $1.12(0.74-1.70)$ \\
\hline \multicolumn{5}{|l|}{ Working status } \\
\hline No & & 1 & 1 & 1 \\
\hline Yes & & $1.68(1.11-2.53)^{*}$ & $1.40(0.93-2.10)$ & $1.59(1.19-2.11)^{* *}$ \\
\hline \multicolumn{5}{|c|}{ Husband/Partner's level of education } \\
\hline No education & & 1 & 1 & 1 \\
\hline Primary & & $1.15(0.72-1.84)$ & $1.47(0.69-3.12)$ & $1.24(0.84-1.83)$ \\
\hline Secondary + & & $2.42(1.50-3.89)^{* * *}$ & $0.99(0.55-1.77)$ & $1.51(1.04-2.19)^{*}$ \\
\hline \multicolumn{5}{|c|}{ Decision on health care } \\
\hline Respondent alone & 1 & 1 & 1 & 1 \\
\hline Res..\& partner & $0.53(0.28-0.98)^{*}$ & $1.45(0.29-7.08)$ & $0.48(0.18-1.28)$ & $0.58(0.28-1.19)$ \\
\hline Partner alone & $0.26(0.14-0.47)^{* * *}$ & $1.35(0.28-6.48)$ & $0.43(0.16-1.16)$ & $0.53(0.25-1.07)$ \\
\hline \multicolumn{5}{|l|}{ Ethnicity } \\
\hline Hausa/Fulani & & 1 & 1 & 1 \\
\hline Other tribes & & $1.85(1.17-2.91)^{* *}$ & $0.75(0.44-1.26)$ & $1.24(0.88-1.75)$ \\
\hline \multicolumn{5}{|l|}{ Pre-natal Attendant } \\
\hline None & 1 & 1 & 1 & 1 \\
\hline Semi-skilled & $6.24(3.77-10.31)^{* * *}$ & $5.31(2.97-9.46)^{* * *}$ & $3.33(0.77-14.31)$ & $4.91(2.89-8.32)^{* * *}$ \\
\hline Skilled & $7.98(5.34-11.91)^{* * *}$ & $5.76(3.64-9.11)^{* * *}$ & $5.06(1.58-16.14)^{* *}$ & $5.71(3.75-8.67)^{* * *}$ \\
\hline \multicolumn{5}{|l|}{ Place of Delivery } \\
\hline Home & 1 & 1 & 1 & 1 \\
\hline Health Facility & $2.57(1.98-3.33)^{* * *}$ & $1.62(1.01-2.57)^{*}$ & $1.95(1.30-2.99)^{* *}$ & $1.77(1.31-2.37)^{* * *}$ \\
\hline -2loglikelihood & 1919.4432 & 1013.413 & 728.529 & 1768.581 \\
\hline Nagelkerke $R^{2}$ & 0.377 & 0.247 & 0.359 & 0.437 \\
\hline
\end{tabular}




\section{Discussion}

Clearly evident in this study and which cannot be under-estimated is the association of household wealth with child immunization status. In this perspective, the prevalence of complete immunization was found to be considerably higher among children of the rich compared to the poor. This finding substantiates the outcome of previous studies. ${ }^{4,6}$ An implication that being rich is protective of complete immunization in the core-North Nigeria and consequently better health - a viscous cycle that could be attributed to underlying pervasive structural inequities and social determinants of health in existing literature. ${ }^{24}$ These findings also establish the existence of health disparities as a result of differences in wealth status in Northern Nigeria. Health disparities/inequalities has been a topic of concern and debate for decades now-described succinctly as differences in health between people with different positions in a socioeconomic hierarchy; not only unnecessary and avoidable but, also considered unfair and unjust. ${ }^{25,26}$ The evident divergence observed with immunization coverage in this study calls attention to the persistent health disparities that exist between poor and rich households in Northern Nigeria.

Optimizing immunization particularly in Northern Nigeria has been daunting due to several factors. Such factors that contribute to this uphill task include the literacy level as evidenced by this study and validating literature. ${ }^{12,27}$ Association of household wealth status with completion of immunization as observed with richer households compared to poorer households was significant for both educational status of respondents' mothers and spouse's educational status. This corroborates the finding from another study. ${ }^{10}$

Religion, media access, prenatal attendants and place of delivery were identified as common predictors of complete immunization among the children of the poor and rich women. These factors have been identified in previous studies as essential to complete immunization among children age 12-23 months. ${ }^{4,6,10}$ The direction and pattern of the relationship of the factors and complete childhood immunization are similar to what exists in literature. ${ }^{4,6,10}$ However, in addition to these factors, other factors were established to be specific to the poor and rich households. Maternal age is a predictor of complete immunization among the rich but not the poor with children of the younger women less likely to receive complete immunization than the children of the older women. Reduction in the odds of child vaccination among younger women has been documented in earlier studies. ${ }^{4,6}$ Experience of older women in childcare provision and knowledge of the benefits of immunization with increasing age are likely possible reasons for this finding. Maternal age which was found to be an insignificant factor among the poor might be a result of dominance of women with no formal education among the poor as observed in this study. The study further showed that, work status, husband's education and ethnicity are the determinants of complete child immunization that are peculiar to the poor. These outcomes are expected since the majority of the rich women who participated in this study are literate, and education is imperative to reduction in the ethnic and husband's education effect on child immunization.

Notably, irrespective of the wealth class, our study demonstrates the relative importance of men as major players with respect to decision making on health related matters. This offers credence to some studies that have been conducted in Northern Nigeria ${ }^{28}$; however refutes literature as men's involvement and decision making was poor in SouthWestern Nigeria. ${ }^{29,30}$ The relative increase in involvement of Northern Nigerian men with decision making for health issues may be explained by the subservient roles expected of women which is still deeply entrenched in the cultural values of the Northern sect. ${ }^{31,32}$ Victoria argues succinctly for the need to consider equity issues very seriously when planning for scale up of interventions relating to immunization for the households in poorest wealth quintiles ${ }^{33}$, if these vulnerable and socially dis-advantaged populations are to be effectively reached and the "inverse care law" is to be halted and reversed.

The findings from this study ought to be considered in view of the noting the following limitations.

\section{Limitations}

First, since our study was conducted as a secondary analysis from a national data set, the authors of this research had no way of ensuring or verifying the authenticity and rigor with ensuring the quality of the data during its collection. Secondly, the study results were generated from a DHS survey which does not collect information specific to income and expenditure. Income and expenditure spe- 
cific questions are indicators used to capture wealth index more appropriately. Instead, asset based wealth profiles that are generated from this study served as a proxy for determining and classifying the households into wealth and non-wealthy households respectively, which might have been subject to a minimal level of bias. ${ }^{34}$

Despite the limitations, the use of the National Demographic Health Survey, a nationally representative and largedata set remains the strength of this study.

\section{Program and policy implications}

The World Health Organization (WHO) has substantiated the focus on improving the health of the most vulnerable and reducing inequalities between population subgroups by stating that "the objective of good health is twofold: the best attainable average level and the smallest feasible differences among individuals". ${ }^{35}$ In view of this, several factors have been implicated as factors underlying health disparities which could be supply or demand oriented factors. ${ }^{36}$ Though, a bit problematic to attribute the disparities with utilization of immunization among poor and rich households to supply or demand side factors, it is important to proffer holistic approaches when formulating policies that not only takes into cognizance the supply and demand factors but also the individual and more complex underlying contextual factors as relate to the household wealth. Some factors established by literature to contribute to such disparities range from barriers to access, underestimation of personal risk and misunderstanding of vaccination risks to mistrust in the health care system. ${ }^{37}$ Notable myths that are propagated against benefits of immunization, such as allegations that the polio vaccination campaign was being used for the purpose of depopulating developing countries, ${ }^{38}$ should be considered and properly addressed in policy formulation at every tier of the government. The impact of population densities in masking or diluting the effects of mass immunization campaigns is equally very pertinent in the formulation of a feasible, sustainable and equitable immunization policy.

Proposed strategies to minimize the disparities between the rich and poor that can be adopted have been summarized. ${ }^{38}$ Nonetheless, special attention should be accorded to culture and dynamics of our local setting. These include: (1) Changes to health care system structural factors that eliminate access barriers. (2) Education to increase awareness and improve demand for vaccines. (3) Participation of community-based organizations to assess local needs and design responsive solutions (4) Support with community financing in form of fee waivers implemented through health cards, micro-credit schemes, vouchers, conditional cash transfers ${ }^{37}$ can help to provide different degrees of insurance against unexpected expenditures and thus reducing demand barriers for poorer households and its accompanying inequalities considerably.

\section{Conclusion}

This study exhibited that health disparities still largely occur that inhibit significantly the completion of immunization between the poor and rich households. Complete immunization was higher among the children of the rich than the poor. These disparities are avoidable, unfair and preventable. Feasible and sustainable policies that take into account dynamics of the local context and culture are advocated for to enable elimination of disparities between the rich and poor households in Nigeria at large. Household wealth is a crucial element to complete immunization among children. It is therefore imperative for policy makers and programme managers to implement effective interventions that consider household wealth as a strategy for full immunization coverage in Nigeria.

\section{Acknowledgements}

The authors thank ICF International for granting the approval of the data used for this study. We also appreciate Centre for Actuarial Research (CARe), University of Cape-Town, Cape-Town, South Africa for sponsoring the visit of Dr. S.A, Adebowale to the University. The manuscript of this paper was drafted and submitted to African Health Sciences during his period of stay in the University.

\section{Funding}

None.

\section{Competing interests}

None declared.

\section{Ethical approval}

Ethical approval was obtained from the Ethical Review Board of the Federal Ministry of Health (NHREC/2013/07) in Nigeria. Informed consent was 
sought from the respondents and granted before the interview was conducted. The respondents were assured of the anonymity and confidentially of the information they provided.

\section{References}

1. WHO. Global Immunization coverage report. 2015. http://www.who.int/immunization/newsroom/press/ immunization_coverage

2. Oyo-Ita A, Wiysonge CS, Oringanje C, Nwachukwu CE, Oduwole O, Meremikwu MM. Interventions for improving coverage of childhood immunisation in lowand middle-income countries. The Cochrane database of systematic reviews. 2016;7:Cd008145. http://doi: 10.1002/14651858.CD008145.pub3

3. WHO. Assessment report of the global vaccine action plan strategic advisory group of experts on immunization. 2006; Available at: http://www.who.int/immunization/global_vaccine_action. Accessed February, 10, 2017 4. Gram L, Soremekun S, Asbroek A, et al. Socio-economic determinants and inequities in coverage and timeliness of early childhood immunization in rural Ghana. Tropical Medicine \& International Health. 2014;19(7):802-11. http:/ / doi.org/10.1111/tmi.12324

5. Abadura SA, Lerebo WT, Kulkarni U, Mekonnen ZA. Individual and community level determinants of childhood full immunization in Ethiopia: a multilevel analysis. BMC Public Health. 2015;15:972. http://doi: 10.1186/ s12889-015-2315-z.

6. Brown VB, Oluwatosin OA.Socio-demographic factors associated with childhood immunization uptake in Akinyele Local Government Area, Oyo State, Nigeria. African Journal of Medicine and Medical Sciences. 2012;41(2):1617. http://doi.org/10.1111/tmi.12324

7. PRB. World Population Data Sheet with a special focus on human needs and sustainable resources. Population Reference Bureau. 2016; Available at: http://www.prb. org. Accessed January 5, 2017.

8. Federal Ministry of Health. Child Survival in Nigeria: Situation, Response, and Prospects. Key Issues POLICY Project/Nigeria October 2002; Available at: http:// www.policyproject. com/pubs / country reports /nig_csrevised.pdf. Accessed December 9, 2016.

9. NPHCDA. National primary health care development agency in Nigeria. 2012. http://www.nphcda.gov.ng. Accessed December 10, 2016.
10. Antai D. Inequitable childhood immunization uptake in Nigeria: a multilevel analysis of individual and contextual determinants. BMC Infectious Diseases. 2009;9(1), 181. http://doi.org/10.1186/1471-2334-9-181

11. Babalola S. Determinants of the uptake of the full dose of diphtheria-pertussis-tetanus vaccines (DPT3) in Northern Nigeria: a multilevel analysis. Maternal and Child Health Journal. 2009;13(4):550-8. http://doi:10.1007/ s10995-008-0386-5

12. National Population Commission (NPC) [Nigeria] and ICF International. Nigeria Demographic and Health Survey 2013. Abuja Nigeria and Rockville, Maryland, USA.

13. Clouston S, Kidman R, Palermo T. Social inequalities in vaccination uptake among children aged 0-59 months living in Madagascar: an analysis of Demographic and Health Survey data from 2008 to 2009. Vaccine. 2014;32(28):3533-9. http://doi:10.1016/j.vaccine.2014.04.030

14. Shrivastwa N, Gillespie BW, Kolenic GE, Lepkowski JM, Boulton ML. Predictors of Vaccination in India for Children Aged 12-36 Months. American Journal of Preventive Medicine. 2015;49(6):S435-44. http://doi:10.1016/j. amepre.2015.05.008

15. Mathew JL. Inequity in childhood immunization in India: a systematic review. Indian Pediatrics. 2012;49(3):20323. https://www.ncbi.nlm.nih.gov/pubmed/22484740

16. Devasenapathy N, Ghosh Jerath S, Sharma S, Allen E, ShankarAH,Zodpey S. Determinants of childhood immunisationcoverage in urban poor settlements of Delhi, India: a cross-sectional study. BMJ Open. 2016;6(8):e013015. http:/ / doi: 10.1136/bmjopen-2016-013015

17. Munthali AC. Determinants of vaccination coverage in Malawi: evidence from the demographic and health surveys. Malawi Medical Journal. 2007;19(2):79-82. https:// www.ncbi.nlm.nih.gov/pmc/articles/PMC3345647/

18. Bhandari P, Shrestha SS, Ghimire DJ. Sociocultural and geographical disparities in child immunization in Nepal. Asia Pac Population Journal. 2007;22:43-64. https:/ / www.popline.org/node/557679

19. Ndirangu J, Bärnighausen T, Tanser F, Tint K, Newell ML. Levels of childhood vaccination coverage and the impact of maternal HIV status on child vaccination status in rural KwaZulu-Natal, South Africa. Trop Med Int Health. 2009;14:1383-93. http://doi:10.1111/j.1365-3156

20. Cui FQ, Gofin R. Immunization coverage and its de- 
terminants in children aged 12-23 months in Gansu, China. Vaccine. 2007;25:664-71. http://doi:10.1016/vaccine 21. Arsenault C, Harper S, Nandi A, Mendoza Rodríguez JM, Hansen PM, Johri M. Monitoring equity in vaccination coverage: A systematic analysis of demographic and health surveys from 45 Gavi-supported countries. Vaccine. 2017 Feb 7;35(6):951-959. http://doi:10.1016/j.vaccine.2016.12.041

22. NPC. 2006. Nigeria population census. National Population Commission. Federal Republic of Nigeria

23. Federal Ministry of Health Nigeria. Comprehensive EPI multi-year plan 2011-2015. Abuja, Nigeria: National Primary Health Care Development Agency; 2011.

24. Olden K, White SL. Health-related disparities: influence of environmental factors. Medical Clinics of North America. 2005;89(4):721-738. http://doi:10.1016/j.mcna 25. American Psychological Association. APA health disparities initiative. 2017; http://www.apa.org/topics/ health-disparities/initiative.aspx. Accessed December 16, 2016.

26. Braveman P. Health Disparities and Health Equity: Concepts and Measurement. Annual Review of Public Health. 2006;27:167-194. http://doi.org/10.1146/annurev.pub lhealth .27 .021405 .102103

27. Taylor YJ, Laditka SB, Laditka JN, et al. Associations of Household Wealth and Individual Literacy with Prenatal Care in Ten West African Countries. Maternal and Child Health Journal. 2016;20(11):2402-2410. http://doi. org/10.1007/s10995-016-2068-z

28. Kabir M, Iliyasu Z, Abubakar IS, Maje BS. The Role of Men in Contraception Decision-making in Fanshekara village, Northern Nigeria. Tropical Journal of Obstetrics \& Gynecology. 2003;20(1):24-27. http://dx.doi.org/10.4314/ tjog

29. Ijadunola MY, Abiona TC, Kay T, et al. Male Involvement in Family Planning Decision Making in llelfe, Osun State, Nigeria. African Journal of Reproductive Health. 2010;14(4):45-52. http://www.bioline.org.br/pdf?rh10064
30. Orji EO, Ojofeitimi EO, Olanrewaju BA. The role of men in family planning decision-making in rural and urban Nigeria. The European Journal of Contraception and Reproductive Health Care. 2007;12(1):70-75. http:// doi:10.1080/13625180600983108

31. Asiyanbola AR. Patriarchy, male dominance, the role and women empowerment in Nigeria. International Population Conference. 2005. http://citeseerx.ist.psu.edu/ doi=10.1.1.424.2583. Accessed January 12, 2017

32. Jegede AS, Odumosu O. Gender and health analysis of sexual behaviour in South-Western Nigeria. Afr J Reprod Health. 2003;7(1):63-70. https://www.ncbi.nlm.nih. gov/pubmed

33. Victora CG, Barros AJD, Axelson H, et al. How changes in coverage affect equity in maternal and child health interventions in 35 Countdown to 2015 countries: an analysis of national surveys. The Lancet. 2012;380(9849):11491156. doi: 10.1016/S0140-6736(12)61427-5. Epub

34. Antai D. Migration and child immunization in Nigeria: individual- and community-level contexts. BMC Public Health. 2010;10, 116. http://doi.org/10.1186/14712458-10-116

35. Holman L, Head ML, Lanfear R, Jennions MD. Evidence of experimental bias in the life sciences: Why we need blind data recording.

36. Fotso JC. Child health inequities in developing countries: differences across urban and rural areas. International Journal for Equity in Health. 2006;5(9). http://doi.org/10. 1186/1475-9276-5-9

37. O'Donnell O. Access to health care in developing countries: breaking down demand side barriers. Cad Sa\{ú\}de P\{úublica. 2007;23(12);2820-2834.

38. Logan JL. Disparities in Influenza Immunization among US Adults. Journal of the National Medical Association. 2009;101(2):161-166. doi:10.1111/j.1532-5415 39. Kaufmann JR, Feldbaum H. Diplomacy and the polio immunization boycott in Northern Nigeria. Health Affairs. 2009;28(4):1091-1101. http://doi:10.1377/ hlthaff.28.4.1091 